\title{
Behavior Intention of Low-carbon Diet: A Perspective of Theory of Planned Behavior
}

\author{
Chenglei LIANG \\ Dongfang College, Shandong University of Finance and Economics, Tai'an, Shandong, China \\ Xiurong LI \\ Shandong University of Finance and Economics, Jinan, Shandong, China
}

\begin{abstract}
Estaing a low-carbon diet lifestyle is not only an important method of promoting health, but also an important means to alleviate global warming, and there is an important significance for harmonious development of man and environment. Based on the theory of planned behavior, this paper constructed the model of low-carbon diet behavior intention, explored the mechanism of the effect of each variable in the model of behavior intention. Statistical results indicated that self-efficacy and facilitating conditions have positively influences on perceived behavioral control, subjective norm, low-carbon dietary attitude and perceived behavioral control have positive effects on behavior intention of low-carbon diet.
\end{abstract}

KEYWORD: TPB; Self-efficacy; Low-carbon diet; Subjective norm

\section{INTRODUCTION}

With the high-speed development of social economy, human diet presents the trend of delicate, diversity and uniqueness, this dietary structure not only affects their health (leading to a variety of chronic disease) and has a tremendous impact on the ecological environment (Riediger, 2007). So the effect of food and diet for ecological environment gradually becomes the focus of attention.

Therefore, eating habits have a significant effect on individual health, ecological environment, but the current relevant research of promoting low-carbon diet is rare, the promotion of the government and related institutions are lack of strength and effectiveness. Therefore the factors that influencing behavior intention of low-carbon diet were discussed in this paper in order to improve dietary habits, and encourage individuals to take more actions of lowcarbon diet, and achieve the purpose of health and ecological environmental protection.

\section{LITERATURE REVIEW}

\subsection{Low-carbon diet}

From the point of view of reducing carbon emissions, low-carbon diet refers to reduce emissions of carbon dioxide from food production to consume, directly or indirectly, in order to alleviate the impact on the environment (González, 2009). The promotion of low-carbon diet is not only for personal health, but also the most simple and practical way to protect the environment.

More and more scholars have realized that greenhouse gas emissions pose a serious threat to the earth, begin to focus on the negative influence on ecological environment caused by eating behavior, but at present the studies for the low-carbon diet are mostly limited to the relationships between health, environmental protection and diet (Norton \& Feber 2009). Those studies emphasized on objective facts too much, paid little attention to the factors affecting the behavior of low-carbon diet, and how to promote a low-carbon diet was seldom involved.

\section{$2.2 T P B$}

In the related research of human behavior, the theory of planned behavior has been widely recognized and supported by scholars. In many fields, such as environmental protection, education, transportation, medicine, social issues, consumer behavior, many scholars have applied this theory to predict and explain individual behavior, and the results of those studies also proved that this theory has a good ability to predict and explain on the individual behavior (Ekinci \& Massey 2008).

The theory of planned behavior thinks that people's behavior intention is the key factor for behavior, attitude, subjective norm and perceived behavioral control has a direct effect on behavioral intention, so if the more positive attitude, the stronger subjective norm and perceived behavioral 
control, personal behavior intention will be stronger(Ajzen, 2002).

The theory of planned behavior had been successfully applied in many fields; this theory was the main theoretical basis of the analysis of individual behavior for many scholars, but the amount of study of low-carbon diet which applied the theory of planned behavior was rare. So this paper used the theory of planed behavior to explore low-carbon dietary behavior, and verify the applicability of the theory in the field of low-carbon diet.

\section{THE RESEARCH MODEL AND HYPOTHESIS}

\subsection{The research model}

This paper chose low-carbon dietary attitude, subjective norm and perceived behavioral control as independent variable based on the theory of planned behavior, to explore their influence mechanism on low-carbon dietary behavior intention, to verify the validity of the theory of planned behavior in low carbon dietary behavior. Increasing two variables of self-efficacy and facilitating conditions, analyzed of how they would affect the model, hoping to continue to enrich and expand planned behavior theory.

\subsection{Hypothesis}

Precious studies argued that attitude would not directly affect actual behavior, but affected individual's behavior intention firstly, and then affected actual behavior (Hrubes, 2001). Subjective norm refers to the perceived social pressure which external reference groups give when an individual takes low-carbon dietary action. As the important reference groups are agree with the behavior, individual behavior intention will be higher.

In real life, people often would be affected by many external non-rational factors and limitations (such as money, time and technology), so some behavioral decisions are not completely controlled by personal will. Behavior does not depend on personal desire or intention, but also is affected by non-motivation factors (Han \& Kim 2010).

Hypothesis 1: Individual' attitude towards lowcarbon dietary behavior, subjective norm, and perceived behavior control has significantly positive effect on behavioral intention of low-carbon diet.

Perceived behavioral control refers to essentially subjective evaluation of internal and external things; the subjective evaluation would be affected by the inner self-cognition. Self-efficacy is one of the individual evaluations of his own ability to deal with everything and is the self-awareness of his own ability and confidents. Self-efficacy would be affected by objective external environment, the selfadjustment, experience, achievements and performance (Kaiser \& Bogner 2005). Self-efficacy will influence the feelings of individuals of perceived behavior control. People with high selfefficacy would think that even if they have fewer resources, they can also successfully complete the task. Facilitating conditions is the degree of controlling over the resources or obstruct when individuals engage in a specific behavior (Quintal, 2010). If the resources needed are more easily obtained, the individual would perceive they have strong control of behavior, and then behavioral intention would be easy to produce.

Hypothesis 2: Self-efficacy and facilitating conditions has significant positive influence on perceived behavioral control.

\section{RESEARCH METHODS}

\subsection{The selection of participants}

The study took the random sampling, and looked for voluntary participation from college students of a university. 360 copies of the questionnaires were distributed and 306 copies of the valid questionnaires were recovered, the effective rate of recovery was $85 \%$, the proportion of men accounted for $60.8 \%$ in all respondents, the proportion of women accounted for $39.2 \%$.

\subsection{The design of questionnaire}

Learning from precious studies and questionnaire, and considering the research framework and content, the study designed targeted questionnaires. The questionnaires were divided into four parts, including low-carbon dietary attitude scale, subjective norm scale, perceived behavioral control scale and low-carbon dietary behavioral intention scale. Perceived behavioral control scale was subdivided into two parts: self-efficacy scale and facilitating conditions scale. The questionnaires all passed through the inspection before test; the results showed the questionnaires had good reliability and validity, and complied with the aim of this article.

\section{RESULTS AND ANALYSIS}

\subsection{The effect of low-carbon dietary attitude, subjective norm and perceived behavioral control on behavior intention of low-carbon diet}

From the table1 we can got the following conclusions, the adjusted $\mathrm{R}^{2}$ was 0.486 , this represented that the three independent variables can explain the amount of change of dependent variables for $47.5 \%$. Standardized regression coefficients of independent variables were all positive, represented all independent variables have positive influence on dependent variable, and the effect reached 
significant level, showed if attitude of low-carbon diet is more positive, the subjective norm is more intense, perceived behavioral control is more higher, the behavior intention of low-carbon diet would be more likely to occur.

The absolute value of standardized regression coefficient is larger, and then the influence of independent variable on the dependent variable would be greater. So it can be seen from the results that the effect of attitude on low-carbon dietary behavior intention is the largest, followed by perceived behavioral control and subjective norms.

Table 1. The summary of regression analysis of behavior intention of low-carbon diet

\begin{tabular}{|l|l|l|l|}
\hline The dependent variable & $\begin{array}{l}\text { Not standardized } \\
\text { coefficient B }\end{array}$ & $\begin{array}{l}\text { Standardized } \\
\text { coefficient } \beta\end{array}$ & t-value \\
\hline Intercept & 17.582 & & 12.304 \\
\hline $\begin{array}{l}\text { Low-carbon diet } \\
\text { attitude }\end{array}$ & 0.798 & 0.301 & 10.500 \\
\hline $\begin{array}{l}\text { Subjective norm } \\
\text { Perceived behavioral } \\
\text { control }\end{array}$ & 1.125 & 0.150 & 7.401 \\
\hline $\mathrm{R}=0.689 \quad \mathrm{R} 2=0.475$ & 0.114 & 3.824 \\
\hline
\end{tabular}

\subsection{The effect of self-efficacy and facilitating conditions on perceived behavioral control}

From the table 2, we can concluded that the adjusted $\mathrm{R}^{2}$ was 0.562 , this results represented that the two independent variables of self-efficacy and facilitating conditions can explain the amount of change of dependent variables for $56.2 \%$. Standardized regression coefficients of independent variables were all positive, represented self-efficacy and facilitating conditions have positive and significant effect on perceived behavioral control.

Table 2. The summary of regression analysis of perceived behavior control

\begin{tabular}{|l|l|l|l|}
\hline $\begin{array}{l}\text { The dependent } \\
\text { variable }\end{array}$ & $\begin{array}{l}\text { Not standardized } \\
\text { coefficient B }\end{array}$ & $\begin{array}{l}\text { Standardized } \\
\text { coefficient } \beta\end{array}$ & t-value \\
\hline Intercept & 14.589 & & 10.08 \\
\hline self-efficacy & 0.549 & 0.199 & 6.949 \\
\hline $\begin{array}{l}\text { facilitating } \\
\text { conditions }\end{array}$ & 0.589 & 0.146 & 4.991 \\
\hline $\mathrm{R}=0.753 \quad \mathrm{R} 2=0.567$ Adjusted $\mathrm{R} 2=0.562 \quad \mathrm{~F}=34.667$ \\
\hline
\end{tabular}

\section{CONCLUSIONS}

Statistical results indicated that self-efficacy and facilitating conditions have positively influences on perceived behavioral control, subjective norm, lowcarbon dietary attitude and perceived behavioral control have positive effects on behavior intention of low-carbon diet. Overall, dependent variables could be explained effectively by independent variables; therefore the constructed model based on the theory of planned behavior could effectively explain and predict behavior intention of low-carbon diet, these results keep the consistent with previous researches (Schau, 2009).

Also some different conclusions were obtained in the study; results showed that the effect of attitude on behavior intention of low-carbon diet is the largest, followed by perceived behavioral control and subjective norm. The conclusions of this point in previous studies were not unified (Dono \& Richardson 2011). The reasons for the results may be related to the differences between low-carbon dietary behavior and other types. The results also may be associated with the design of questionnaire, the description of subjective norm in the questionnaire may make the participants have no true feelings of the social pressure given by external reference groups; therefore these possible reasons weakened the effect of subjective norm on behavior intention.

\section{MANAGEMENT SUGGESTIONS}

Individual attitude towards things are acquired through learning, the same is true for low-carbon dietary behavior. Therefore, we can make use of low-carbon dietary education to change public attitudes towards low-carbon diet. In the process of education, to give the public a basic knowledge of low-carbon diet, and to make they have more indepth understanding of low-carbon diet. It is necessary to emphasize the benefits of low-carbon diet for the individual, such as a strong body, away from the disease, also to emphasis benefits for environment. These measures can enhance personal awareness and sense of responsibility for the environment, cultivate and establish positive attitude of dietary behavior.

The public often would be affected by surroundings or social pressure, for example, students, parents, teachers, friends, family or supervisor and TV commercials or newspaper and magazine. So the government can influence the public surroundings or provide the social atmosphere that is helpful to enhance the public's behavior intention. Relevant institutions can select attractive and professional spokesperson to spread the concept of low-carbon diet. And offer low-carbon diet lectures or on-site activities to influence public' attitude of low-carbon diet.

Perceived behavioral control has an important influence on behavior intention of low-carbon diet, so the government and relevant organizations should make the public aware of that it is not difficult to perform the behavior of low-carbon diet. Spreading more knowledge and experience of low-carbon diet to reduce the expected obstacles, for example, improving the convenience of low-carbon diet; 
reducing the cost of money and energy of lowcarbon diet. And the government should enhance public' confidence in the low carbon diet through the way of on-site experience, and continue to reward and encourage people to engage in low-carbon dietary behavior.

\section{RESEARCH LIMITATIONS AND FUTURE DIRECTIONS}

In this paper, using a questionnaire method to collect dates, each scale were designed on the basis of reference of previous studies, but subjects were inevitably interfered by external factors. So sometimes it is difficult to obtain the true inner thoughts of experimental subjects. The subsequent can use the way of combination of quantitative and qualitative research (such as increasing the openness of topics in the questionnaire, in-depth interviews) in the future research, this can strengthen the internal validity of the questionnaire, still can get more objective results, and a deeper understanding of the subjects' inner true idea can be obtained.

This study only discussed the behavior intention of low-carbon diet, no further to explore the correlation between behavior intention and actual behavior, so it is suggested that future researchers can track the subjects behavior of low-carbon diet in life, to explore the degree of influence of attitude, subjective norm and perceived behavioral control on actual behavior, and to construct a complete model of low-carbon dietary behavior. Although the theory of planned behavior has been proven to be quite effective in predicting behavior intention by many scholars, but the influencing factors of low carbon dietary behavior are very complicated, in addition to the psychological factor, there are many external factors, the follow-up research can continue to explore the behavior of low-carbon diet combining with other influencing factors.

\section{REFERENCES}

[1] Ajzen, I. 2002. Perceived behavioral control, self-efficacy, locus of control and the theory of planned behavior. Journal of Applied Social Psychology32 (4): 665-683.

[2] Dono, J. \& Richardson, B. 2010. The relationship between environmental activism, pro-environmental behavior and social identity. Journal of Environmental Psychology30:178 186.

[3] Ekinci. Y. \& Massey, G.R. 2008. An extended model of the antecedents and consequences of consumer satisfaction for hospitality services. European Journal of Marketing42 $(1 / 2): 35-68$.

[4] González A.D. 2009. Potential contributions of food consumption patterns to climate change. AMJ ClinNutr89:1704-1709S.

[5] Han, H. \& Kim, Y. 2010. An Investigation of Green Hotel Customers' Decision Formation-Developing an Extended Model of the Theory of Planned Behavior. International Journal of Hospitality Management29 (4):659-668.

[6] Hrubes, D. \& Daigle, J. 2001. Predicting hunting intentions and behavior: An application of the theory of planned behavior. Leisure Science23: 165-178.

[7] Kaiser, F.G. \& Bogner, F.X. 2005. Contrasting the theory of planned behavior with the value-belief-norm model in explaining conservation behavior. Journal of Applied Social Psychology35 (10):2150 2170

[8] Norton, L. \& Feber, R. 2009. Consequences of organic and non-organic farming practices for field, farm and landscape complexity. Agriculture, Ecosystems and Environment 129(1e3):221-227.

[9] Quintal, V. A \& Soutar, G.N. 2010. Risk, uncertainty and the theory of planned behavior: A tourism example. Tourism Management31 (6): 797-805.

[10]Riediger, N.D \& Moghadasian, M.H. 2007. The influence of social demographic factors on patterns of fruit and vegetable consumption in Canadian adolescents. Journal of the American Dietetic Association107: 1511-1518.

[11]Schau E.M. \& Aanondsen S.A. 2009. Energy consumption in the Norwegian fisheries. Journal of Cleaner Production 17:325-340. 